\title{
Los programas sociales como mecanismos de “represión desapercibida” en Argentina (2007-2019). Un análisis desde las políticas de las sensibilidades
}

\author{
Adrián Scribano \\ CONICET, Universidad de Buenos Aires, Buenos Aires, Argentina. \\ Email: adrianscribano@gmail.com \\ Angélica De Sena \\ Universidad de La Matanza, Universidad de Buenos Aires, Buenos Aires, Argentina. \\ Email: angelicadesena@gmail.com
}

\begin{abstract}
Resumen: Al menos en los últimos 16 años se ha extendido la idea de que en Argentina ha crecido la politización, la participación social y política, se ha democratizado el aparato represivo y se ha experimentado una ampliación de derechos. La contracara de dicha "representación” es, justamente, la negación de aquellos atributos, reclamando atención sobre los procesos de represión, silenciamiento y vulneración de derechos. En base al análisis de datos primarios y secundarios, cuantitativos y cualitativos, este trabajo busca constatar la no participación y no politización como prácticas sociales extendidas, sintetizar la masividad de las políticas sociales como una vía para construir sociabilidades y discutir, desde la mirada de los sujetos, las emociones que constituyen las políticas de las sensibilidades asociadas a esos dos procesos. Concluimos que la "represión desapercibida" que implica la dependencia, el individualismo y el consumo autocentrado hacen de la represión física un mecanismo reservado para momentos y actores muy específicos, más allá que sea o no importante en su número.
\end{abstract}

Palabras clave: Participación; programa social; emociones; sensibilidades; sociología.

\section{Social programs as mechanisms of "unnoticed repression" in Argentina (2007-2019). An Analysis from the sensitivity Policies}

\begin{abstract}
At least in the last 16 years the idea has spread that in Argentina politicization, social and political participation has grown, the repressive apparatus has been democratized and there has been an expansion of rights. The other side of this "representation" is, precisely, the negation of those attributes, demanding attention on the processes of repression, silencing and violation of rights. Based on the analysis of primary and secondary, quantitative and qualitative data, this work seeks to verify non-participation and non-politicization as extended social practices, to synthesize the massiveness of social policies as a way to construct sociabilities and to discuss, from the perspective of the subjects, the emotions that constitute the policies of the sensitivities associated with these two processes. We conclude that the "unnoticed repression” implied by dependence, individualism and self-centered consumption make physical repression a mechanism reserved for very specific moments and actors, regardless of whether or not it is important in its number.
\end{abstract}

Keywords: Participation; social program; emotions; sensitivities; sociology

\section{Programas sociais como mecanismos de "repressão despercebida" na Argentina (2007-2019). Uma análise desde as políticas das sensibilidades}

Resumo: Pelo menos nos últimos 16 anos, cresceu a ideia de que na Argentina a politização, a participação social 
e política cresceram, o aparato repressivo foi democratizado e sem tem experimentado uma expansão dos direitos. O outro lado da dita "representação" é justamente a negação desses atributos, demandando atenção nos processos de repressão, silenciamento e violação de direitos. Com base na análise de dados primários e secundários, quantitativos e qualitativos, este trabalho busca verificar a não-participação e não-politização como práticas sociais estendidas, sintetizar a massividade das políticas sociais como uma forma de construir sociabilidades e discutir, dos olhos dos sujeitos, as emoções que constituem as políticas das sensibilidades associadas a esses dois processos.

Concluímos que a "repressão despercebida" que implica a dependência, o individualismo e o consumo autocentrado fazem da repressão física um mecanismo reservado para momentos e atores muito específicos, independentemente de ser importante ou não quantitativamente.

Palavras-chave: Participação; programa social; emoções; sensibilidades; sociologia.

\section{Introducción}

Al menos en los últimos 16 años se ha extendido la idea de que en Argentina ha crecido la politización, la participación social y política, se ha democratizado el aparato represivo y se ha experimentado una ampliación de derechos. La contracara de dicha "representación”, es justamente la negación de aquellos atributos, reclamando atención sobre los procesos de represión, silenciamiento y vulneración de derechos.

Luego de mostrar la casi inexistente participación política y social en la Argentina de los últimos 16 años, el presente artículo se interroga sobre cuáles son las emociones asociadas a dicho fenómeno.

En el marco del desarrollo de las democracias por consumo y las formas de explotación asistida, se ha profundizado la falta de implicación de los sujetos en los partidos políticos y en las protestas sociales (Scribano, 2017, 2018). Si bien es posible constatar la existencia de "grandes movilizaciones" multipartidarias, multisectoriales e interseccionales (géneros, razas, edades), a la hora de formar parte de una institución o colectivo las personas performan una in-acción: el no participar.

En el mismo sentido, desde el año 2001 han existido ciclos de protestas y represiones estatales e institucionalizadas. El vehículo de gestión conflictual que se ha priorizado son las políticas sociales y, con ellas, se ha construido una particular política de la sensibilidad que a) reemplaza las formas de violencia corporal como único medio de represión y b) limita la protesta social a la demanda de más programas sociales bajo la estrategia narrativa de pedir mayor "sensibilidad" por parte del gobierno.

En el marco de lo reseñado, este trabajo busca a) constatar la no participación y no politización como prácticas sociales extendidas, b) sintetizar la masividad de las políticas sociales como una vía para construir sociabilidades y c) discutir, desde la mirada de los sujetos, las emociones que constituyen las políticas de las sensibilidades asociadas a esos dos procesos.

Donde protesta o participación hubo, plan social queda. La "represión desapercibida" que implica la dependencia, el individualismo y el consumo autocentrado hacen de la represión física un mecanismo reservado para momentos y actores muy específicos, más allá que sea o no importante en su número.

El presente artículo se inscribe en trabajos anteriores donde hemos evidenciado el cruce entre una sociología de los cuerpos/emociones (Scribano, 2018, 2017a) y una sociología de las políticas sociales (De Sena, 2017, 2016, 2014, 2011) que parten del diagnóstico que en las últimas décadas estamos viviendo la consolidación de sociedades normalizadas en el disfrute inmediato a través del consumo.

Nuestra intención es hacer evidente cómo se conectan los procesos de estructuración social, las modificaciones en la economía política de la moral y las políticas de las sensibilidades. Las políticas de las sensibilidades son comprendidas como el conjunto de prácticas sociales cognitivo-afectivas tendientes a la producción, gestión y reproducción de horizontes de acción, disposición y cognición. Dichos horizontes refieren: i) la organización de la vida cotidiana (día-a-día, vigilia/sueño, comida/abstinencia, etc.); ii) las informaciones para 
ordenar preferencias y valores (adecuado/inadecuado; aceptable/inaceptable; soportable/insoportable); y iii) los parámetros para la gestión del tiempo/espacio (desplazamiento/emplazamiento; murallas/puentes; infraestructura para la valorización del disfrute).

En lo que sigue proponemos que la baja participación y la masificación de los programas sociales han devenido en un paisaje de gestión de las emociones a través de políticas de las sensibilidades que hacen cuerpo/ emoción las represiones desapercibidas.

\section{Participación política, emociones y acciones colectivas}

En los procesos de expansión a escala global de la actual economía política de la moral el desprestigio de la política y la consolidación de sociedades normalizadas en el disfrute inmediato a través del consumo está asociada al miedo, al hartazgo y a la resignación que produce la consolidación de una democracia por consumo y una explotación asistida (Scribano, 2018). En este marco, conectar participación, emociones, acciones colectivas y represión demanda, al menos, un conjunto de aproximaciones y aclaraciones previas que permitan conectar sensibilidades y prácticas individuales y colectivas.

Si nos acercamos a la idea de participación a través de los diccionarios nos encontramos con una expresión resbaladiza. Lincoln, en el "Diccionario Conciso de Políticas y Relaciones Internacionales", afirma respecto de la participación política:

"El nivel general de participación en una sociedad es la medida en que las personas en su conjunto están activas en la política: el número de personas activas multiplicado por la cantidad de su acción, para decirlo aritméticamente. Pero la cuestión de qué es participar en la política es enormemente compleja y, en última instancia, ambigua” (Lincoln, 2018, p.536).

Desde otra perspectiva Nelson (2001) sostiene que la participación política se orienta a influir en las decisiones gubernamentales. Otro de los posibles sentidos de la participación lo encarna la inclusión en los diversos contextos de deliberación ciudadana donde la práctica aludida le da concreción (Thompson and Komporozos-Athanasiou 2015; Montana 2017; Fraser, 2016).

En este trabajo, analizaremos la participación como involucramiento de los sujetos en prácticas colectivas por ellos reconocidas, y utilizaremos datos primarios y secundarios, cuantitativos y cualitativos, provenientes de nuestras investigaciones en Argentina.

Existe sobrada evidencia, proveniente de investigación empírica así como de desarrollos teóricos, que muestra las profundas conexiones entre las emociones y las acciones colectivas. En tal sentido, puede señalarse un conjunto de trabajos que indican las diversas conexiones entre política y emociones. Una perspectiva es la que ofrecen Hutchison y Bleiker (2014) y Linklater (2014) en el plano del mundo de las relaciones internacionales; otra es la modalidad que Boler (2015) encuentra para conectar política feminista, educación digital y emociones. También es posible encontrar investigaciones que relacionan la vida académica, el contexto neoliberal y las emociones (Askins y Blazek, 2017), o los estudios sobre el lugar de las mujeres en la política en el contexto de emociones e identidades colectivas (Hamilton, 2010).

En conexión con los objetivos de este trabajo, existen numerosos estudios que articulan emociones y represión(es). Como sostiene Romanos (2011) en su trabajo sobre el activismo anarquista durante el Franquismo: "Diversos trabajos han señalado cómo en contextos altamente represivos el surgimiento y la continuidad del activismo no se entienden sin la intervención de fuertes elementos subjetivos, afectivos y emocionales.” (Romanos, 2011, p.87) En esta misma línea, se destacan trabajos que conectan contextos represivos, emociones e identidades, como el de Einwohner (2006) sobre la resistencia en el gueto de Varsovia, o aquellos que articulan técnicas represivas, emociones y políticas de las sensibilidades (Scribano, 2010a). 
Asimismo, es necesario reparar en los numerosos trabajos sobre protestas, movimientos sociales, acciones colectivas y emociones en Latinoamérica entre los cuales, solo como ejemplo, se pueden mencionar los siguientes: Fernández Poncela, 2013; García-Martínez, Guzmán-Sala, y Marín-Sandoval, 2016; Colin, 2016; Poma, 2014; Poma y Gravante, 2015a, 2015b, 2016, 2017; Lisdero, 2012, 2017a, 2017b; Vergara, 2018; Cervio y Vergara, 2017 y Cervio, 2015.

En el contexto de la discusión clásica sobre los “nuevos movimientos sociales”, es posible encontrar otras articulaciones e indicaciones con respecto a las relaciones entre emociones y acciones colectivas. En principio, a comienzos de la década de 1980 en Europa, las mencionadas conexiones implican la búsqueda de formas alternativas de participación y decisión política para resolver los problemas más cercanos a la intimidad de las personas, en relación con la crisis de representatividad de las instituciones de las democracias occidentales (Melucci, 1989). En esta escuela de pensamiento se ubican las teorías de Alberto Melucci sobre la "identidad colectiva”, que entiende los movimientos sociales como construcciones sociales. Para Melucci, los significados se construyen dentro de los grupos que participan en el movimiento y, en este sentido, la formación de una identidad colectiva es el tema central (Rebughini y Scribano, 2018)

En el mismo contexto de discusión McAdam (1998) trabaja principalmente con la noción de “liberación cognitiva”; Gamson (1990) la conexión entre “paquetes ideológicos” y medios de comunicación social.

Las investigaciones teórico-empíricas que movilizan los estudios sobre la acción colectiva y los movimientos sociales, junto con los estudios sobre la sensibilidad y las emociones, parten de una premisa fundamental: ambos aspectos están en interrelación y correspondencia permanente, aunque a menudo se investigan por caminos paralelos y diferenciados.

Desde algunas perspectivas, las emociones consideradas "positivas” -como los sentimientos de amor, lealtad, orgullo, entusiasmo, etc. - o las “negativas” -tales como el odio, el miedo, la ira, la tristeza, la vergüenza, etc.- están condicionadas culturalmente. Es decir, las sociedades establecen sus propias normas de regulación de las emociones según el marco “moral-ideológico” en el que se forman, lo que establece su desarrollo particular en diferentes coyunturas o en las formas que adoptan públicamente. Ahora bien, estos marcos se establecen en función de las interacciones que los mismos individuos construyen; fuente de las relaciones afectivas que, a su vez, permiten la generación de nuevos marcos sociales y cognitivos. En otras palabras, "la emoción solo puede manifestarse incrustada en vínculos de sociabilidad, ya que es el conocimiento de estos vínculos y de estas relaciones lo que proporciona la posibilidad misma de esa emoción” (Daich et al. 2007, p. 77).

Se identifican también esfuerzos por esbozar una periodización de cómo las políticas de las sensibilidades y las características fundamentales de las acciones colectivas están interrelacionadas en Latinoamérica, al menos en la segunda parte del siglo XX. En este sentido, Scribano (2017) propone la siguiente síntesis: la década de los 70 está marcada por la violencia como lenguaje y práctica del sentir, en la que los límites de los derechos humanos fueron reducidos y destruidos. Los años 80, después de la Guerra de Malvinas y el “retorno” de la democracia, se formaron entre la expectativa de “lo nuevo” y el miedo a "lo viejo”. La década de los 90 se construyó sobre las contradicciones entre “todos por sí mismos” y la eliminación de los vínculos colectivos tradicionales. La década de 2000 dio forma a las sensibilidades de crisis, fantasmas, fantasías y renuncias. Por su parte, la última década estuvo impregnada de una fuerte reestructuración de las sensibilidades que giran en torno al consumo compensatorio, la transformación de los movimientos sociales en ONG (Organizaciones No Gubernamentales) y la búsqueda, por parte del Estado y del sector privado, de vender y facilitar el disfrute inmediato. En este marco, el autor sostiene que los años de la década de 2000 se caracterizan por las "sensibilidades melancólicas” (sabemos que algo se ha perdido pero no sabemos qué). En una forma elíptica, la pérdida, la desorientación, la falta, la desestructuración y la movilización se convirtieron en componentes de los cimientos de una sociedad resignada, pero “permanentemente” en movimiento. En el contexto de la politización de los derechos económicos y de género, crecieron la incertidumbre y la precariedad. Finalmente, en los últimos siete años surgieron las “sensibilidades normalizadas” en la forma de la elaboración de una religión neocolonial y la expansión del disfrute inmediato a través del consumo. 
En el marco de lo presentado, en el próximo apartado intentaremos reconstruir la situación actual de las conexiones posibles entre disminución de la participación, masividad de los programas sociales y políticas de las sensibilidades.

\section{Elisión conflictual y retraimiento}

En esta sección presentamos información disponible sobre no participación en Argentina en general, primero, y en la Ciudad Autónoma de Buenos Aires y La Matanza, después. La intensión de lo que sigue es que se observe la consistencia de información provenientes de distintas fuentes, territorios y años.

\section{Participación en Argentina}

A pesar de que existe información regional (Latinbarómetro, 2013) y nacional (De Sena, 2014) respecto de las transformaciones y el descenso de la participación política, en los últimos años existe una mirada ingenua/cómplice que se inscribe claramente en la construcción de las fantasías sociales. En Argentina, desde hace más de una década, la participación social y política ha descendido a niveles muy bajos. Los partidos políticos, las asociaciones de vecinos y el resto del entramado socio-participativo -pensado en el diseño de una sociedad democrática para servir como vehículos de conexión entre la sociedad civil, el Estado y el gobierno- vive una situación de deterioro. Las consecuencias básicas de este proceso son: disminución de la implicación en actividades colectivas institucionales, aislamiento y retraimiento.

Si se analizan datos de fuentes diversas, y a través de los años, se descubre el siguiente escenario y panorama.

En el año 2007, el Observatorio de la Deuda Social publicó un documento titulado “Confianza pública y participación ciudadana en la Argentina post-devaluación” donde expresa:

"La mejora que ha registrado la confianza ciudadana en las principales instituciones del sistema político no pareció ir acompañada por un comportamiento similar respecto de la participación cívica, que pese al ligero incremento observado en las actividades asociativas, mostró una baja en términos generales. Efectivamente, la participación en actividades asociativas (sindicales, gremiales y político-partidarias) arrojó un leve aumento entre junio de 2004 y junio de 2006, aunque manteniéndose en niveles muy bajos (5\%). En cuanto a la diferenciación por estrato, se observó una mayor participación en estas actividades por parte de las personas pertenecientes a sectores sociales medios, especialmente medios altos. Es significativo el hecho de que el 93\% de los entrevistados en ambos momentos de medición permaneció sin participar en estas actividades, siendo los cambios brutos en consecuencia muy poco frecuentes. La participación en organizaciones vecinales también se mantuvo en niveles bajos (3\%), pero sin registrar cambios estadísticamente significativos en relación a junio de 2004. A diferencia de la participación en actividades asociativas, la participación en esta clase de actividades es más frecuente en los estratos bajos” (Lépore y Moreno 2007, p. 6).

Por su lado, el Barómetro de las Américas, desde otra perspectiva, en el año 2012 informa:

"En primer lugar, es evidente que los argentinos muestran un nivel comparativamente bajo de participación comunitaria. Como se aprecia en el gráfico (lado izquierdo), Argentina apenas obtiene 14,2 puntos en nuestra escala. Este valor se ubica 12 puntos por debajo del promedio regional y representa casi 10 puntos menos que el promedio registrado para Brasil, el país del Cono Sur de América Latina que obtiene el puntaje más alto” (Lodola y Seligson 2013, p.50).

La misma fuente continúa afirmando:

"Pasando ahora al análisis más detallado de la participación de los argentinos en diferentes organizaciones sociales y políticas, (...) primeramente se vincula con organizaciones religiosas [22.3\%], seguida 
por asociaciones de padres de familia [15.1\%], grupos deportivos [14.5\%], comités o juntas de mejoras [5\%], partidos políticos [4.6\%], grupos de mujeres [3.7\%] y, por último, asociaciones de profesionales [3\%]. Vale la pena señalar que, en promedio, la asistencia a reuniones de organizaciones religiosas casi quintuplica la asistencia a reuniones de partidos o movimientos políticos” (Lodola y Seligson, 2013, p. 51).

En otro sentido, pero con números también coincidentes, el informe Latinbarómetro (más allá de su mirada optimista) es muy claro respecto a marcar las distancias entre el decir y el hacer: "La participación política convencional, sin embargo tiene menos adherentes que la gente que habla de política. El firmar una petición, asistir a manifestaciones o trabajar para un partido son actividades que cerca del $\mathbf{9 0} \%$ de la población no hace" (Latinbarómetro 2013, p. 40 énfasis nuestro).

Estas primeras tres fuentes nos llaman la atención sobre la no participación y sobre la diferencia entre "hablar sobre política” y "hacer en política”; cuestión que nos remite a la ya enunciada creación de fantasías en un régimen democrático y a su posible vinculación con la "represión desapercibida” que ello implica.

\section{Participación en la Ciudad Autónoma de Buenos Aires}

A continuación, se presentan/sistematizan las lecturas de frecuencias de respuestas obtenidas en la "Encuesta sobre el estado de las sensibilidades en la Ciudad Autónoma de Buenos Aires”, diseñada por el Grupo de Estudios sobre Sociología de la Emociones y los Cuerpos del Instituto de Investigaciones Gino Germani de la Universidad de Buenos Aires (UBA). El instrumento fue aplicado en forma domiciliaria en los años 2010, $2012^{1}$ y 2014 a una muestra intencional de 150 adultos en cada año.

Nuestra intención aquí es “enfatizar”, utilizando una “política de estilo” descriptiva y detallada, la fuerte conexión de las respuestas consignadas con nuestro diagnóstico de normalización.

Ante la pregunta:

\section{En los últimos doce meses, ¿̇ha participado en una manifestación o protesta pública?}

\begin{tabular}{|c|c|c|c|}
\hline & $\mathbf{2 0 1 0}$ & $\mathbf{2 0 1 2}$ & $\mathbf{2 0 1 4}$ \\
\hline SI & $35,2 \%$ & $36,2 \%$ & $26,6 \%$ \\
\hline No & $64,8 \%$ & $63,8 \%$ & $73,4 \%$ \\
\hline
\end{tabular}

Fuente: Elaboración propia.

En otra de las preguntas se indagó respecto de las situaciones que llevarían al sujeto a participar en acciones de protesta. A continuación se muestran las respuestas obtenidas ante la posibilidad de que cierren el colegio de su hijo, en la que se observó una tendencia similar entre los años 2010 y 2012, pero con diferencias en el 2104.

• 2010: “sin dudas saldría” a protestar un 51,4\% de los encuestados, “quizás saldría” un 34,5\% y "no saldría nunca” un $11,3 \%$.

· 2012: “sin dudas saldría” un 51,7\%, “quizás saldría” un 37,6\% y "no saldría nunca” un 10,1\%.

· 2014: "sin dudas saldría” un 51,3\%, “quizás saldría” un 26,6\% y "no saldría nunca” un 19,5\%.

Este último porcentaje aumentó respecto a los años anteriores en tanto el segundo disminuyo.

La siguiente situación planteada: Si lo echan del trabajo:

· 2010: un 45,8\% de los encuestados "sin dudas saldría”, el 34,5\% “quizás saldría” y el 18,3\% "no saldría nunca”. 
• 2012: el 44,3\% “quizás saldría”, el 36,2\% “sin dudas saldría” y el 18,1\% “no saldría nunca”.

· 2014: el 44,2\% “quizás saldría”, el 32,5\% "sin dudas saldría” y el 21,4\% “no saldría nunca”.

A continuación: Si los militares quieren tomar el poder:

- 2010: los encuestados indicaron que "sin dudas saldría” el 73,2\%, “quizás saldría” el 14,8\% y “no saldría nunca” el 10,6\%.

· 2012: "sin dudas saldría” un 73,2\%, "quizás saldría” un 14,1\% y "no saldría nunca” un 12,1\%.

• 2014: el 23,4\% “sin dudas saldría”, el 59,1\% “quizás saldría”, y el 14,9\% “no saldría nunca”.

En este caso, en el año 2014 se observa un cambio de tendencia en las tres opciones, aunque resulta relevante indicar que la opción "sin duda saldría" baja del 73,2\% al 23,4\%, aumentando el "quizás saldría”.

Otra posibilidad: Si unos ladrones mataran a un vecino:

• 2010: "sin dudas saldría” un 37,3\%, "quizás saldría” un 46,5\% de los encuestados, y "no saldría nunca” un $14,1 \%$.

• 2012: "sin dudas saldría” un 50,3\%, “quizás saldría” un 37,6\% y "no saldría nunca” un 12,1\%.

· 2014: “sin dudas saldría” un 37,0\%, “quizás saldría” un 49,4\% y "no saldría nunca” un 12,3\%.

Para apoyar una medida del Gobierno:

• 2010: "sin dudas saldría” un 14,1\%, "quizás saldría” un 42,3\% y "no saldría nunca” un 41,5\%.

• 2012: "sin dudas saldría” un 16,1\%, “quizás saldría” un 37,6\% "no saldría nunca” un 44,3\%.

· 2014: "sin dudas saldría” un 13,6, "quizás saldría” un 38,3\% y "no saldría nunca” un 45,5\%. En este caso hay una diferencia notable respecto de los puntos anteriores, dado que baja notablemente el porcentaje para la opción "sin duda saldría" y aumenta el "no saldría nunca" en las tres ondas de la encuesta.

Frente al escenario si el encuestado o un miembro de su familia fuera objeto de un hecho de violencia indican:

• 2010 “sin dudas saldría” el 50\%, “quizás saldría” el 33,1\% y “no saldría nunca” el 14,1\%.

· 2012: “sin dudas saldría” el 57\%, “quizás saldría” el 30,9\%) y “no saldría nunca” el 12,1\%.

· 2014: "sin dudas saldría” el 51,9\%, “quizás saldría” el 40,3\% y “no saldría nunca” 7,1\%, esta última opción baja a partir del 2010.

Para apoyar la ley de legalización del aborto, los encuestados responden en

· 2010: "sin dudas saldría” el 50\%, “quizás saldría” el 27,5\% y “no saldría nunca” el 20,4\%.

- 2012: "sin dudas saldría” el 34,9\%, “quizás saldría” el 35,6\%, y “no saldría nunca” el 26,8\%.

• 2014, "sin dudas saldría” el 30,5\%, “quizás saldría” el 29,9\% y "no saldría nunca” el 35,7\% de los encuestados.

En este caso es notoria la baja del porcentaje de respuestas para la opción "sin dudas saldría" y el aumento en la opción "no saldría nunca”; ello más aun si se considera que durante el año 2018 se produjo una fuerte movilización de la población en relación con esta temática.

Respecto a la opción por los precios de las cosas:

· 2010: “sin dudas saldría” el 13,4\%., “quizás saldría” el 34,5\% y “no saldría nunca” el 46,5\%.

• 2012: "sin dudas saldría” el 16,8\%, “quizás saldría” el 47,7\% y “no saldría nunca” el 35,6\%.

· 2014: "sin dudas saldría” el 14,3\%, “quizás saldría” el 33,8\% y “no saldría nunca” el 50\%. 
Respecto a por una televisión gratuita para todos, las respuestas fueron:

• 2010: “sin dudas saldría” el 16,2\%, “quizás saldría” un 25,4\% y "no saldría nunca” un 55,6\% de los encuestados.

• 2012: “sin dudas saldría” el 8,7\%, “quizás saldría” el 16,8\% y “no saldría nunca” el 73,2\%.

· 2014: “sin dudas saldría” el 9,1\%,“quizás saldría” el 22,1\% y “no saldría nunca” el 67,5\%,

Es menester considerar el bajo porcentaje que acumuló la opción “sin dudas saldría” respecto al resto de las situaciones arriba consideradas.

Para apoyar el fin de la minería a cielo abierto:

· 2010: “sin dudas saldría” el 39,4\%, “quizás saldría” el 32,4\% y “no saldría nunca” el 21,8\%.

· 2012; “sin dudas saldría” el 40,9\%, “quizás saldría” el 34,9\% y “no saldría nunca” el 21,5\%.

· 2014: “sin dudas saldría” el 22,7\%, “quizás saldría” el 40,9\% y “no saldría nunca” el 31,8\%.

Ante el cierre de una empresa los encuestados respondieron:

• 2010: “sin dudas saldría” el 12\%, “quizás saldría” el 35,2\% y “no saldría nunca” el 47,2\%.

· 2012: “sin dudas saldría” el 14,8\%, “quizás saldría” el 43,0\% y “no saldría nunca” el 39,6\%.

· 2014: “sin dudas saldría” el 12,3\%, “quizás saldría” el 35,1\% y “no saldría nunca” un 50\%.

Más allá del estilo seleccionado, no es difícil advertir que existe un marcado proceso de retraimiento y desplazamiento autocentrado de las prácticas de los sujetos y sus sensibilidades. En tal sentido, los datos anteriores permiten asumir que los encuestados:

a) No participan; y si lo hacen no es con frecuencia.

b) Cuando están dispuestos a "salir”, se repite el esquema de "proximidad a la problemática” como clave de la propensión a involucrarse "sólo con lo que me afecta”.

Estas dos sencillas conclusiones interpretativas sobre el análisis consignado nos hacen pensar, aún más, que nuestro diagnóstico sobre la normalización en el disfrute a través del consumo es adecuado.

\section{La (no) participación en La Matanza}

Durante el segundo semestre del 2018 se realizó una encuesta domiciliaria a personas de 18 años y más, semiestructurada con una muestra probabilística de hogares censales, consistente en la selección de 51 radios mediante el método tríetapico y PPS (Proportional to Population Size) en todo el partido de La Matanza (Buenos Aires), obteniéndose 822 casos $^{2}$. En dicho cuestionario se realizaron una serie de preguntas referidas a la participación de los encuestados en distintas instituciones barriales: sociedades de fomento, centro vecinal, partidos políticos, organizaciones barriales o territoriales, delegaciones municipales, parroquias o iglesias, comedores comunitarios, sindicatos u otras ${ }^{3}$.

La primera información que emerge es la baja o nula participación en todas las instituciones mencionadas, tal como se observa en la Tabla 1. La mayor afluencia participativa se registra en parroquias/ iglesias, las cuales acumulan el 10,9\% de las respuestas, mientras que el resto oscila entre el 1,6\% y el 0,1\%. 
Tabla 1.

Participación en instituciones del barrio. Personas de 18 años y más que residen en La Matanza (2018). En porcentajes

\begin{tabular}{|c|c|c|c|}
\hline Institución del banio en la que participa & Si & No & Total \\
\hline Actualmente participa de sociedad de fomento de su barrio & 1,6 & 98,4 & $\begin{array}{l}100 \\
(819)\end{array}$ \\
\hline Actualmente participa del centro vecinal de su banio & 0,5 & 99,5 & $\begin{array}{c}100 \\
(819)\end{array}$ \\
\hline Actualmente participa de partidos políticos en su barrio & 0,7 & 99,3 & $\begin{array}{c}100 \\
(820)\end{array}$ \\
\hline $\begin{array}{l}\text { Actualmente participa de organizaciones } \\
\text { baniales/tenitoriales en su banio }\end{array}$ & 1,0 & 99,0 & $\begin{array}{c}100 \\
(820)\end{array}$ \\
\hline $\begin{array}{l}\text { Actualmente participa de delegaciones municipales en su } \\
\text { banio }\end{array}$ & 0,5 & 99,5 & $\begin{array}{c}100 \\
(820)\end{array}$ \\
\hline Actualmente participa de Parroquia/Iglesia en su barrio & 10,9 & 89,1 & $\begin{array}{l}100 \\
(819)\end{array}$ \\
\hline Actualmente participa del comedor comunitario en su barrio & 1,3 & 98,7 & $\begin{array}{c}100 \\
(820)\end{array}$ \\
\hline Actualmente participa del sindicato en su barnio & 0,1 & 99,9 & $\begin{array}{c}100 \\
(820)\end{array}$ \\
\hline
\end{tabular}

Fuente: Elaboración propia.

A continuación, se analiza la frecuencia de dichas participaciones, en tanto es por demás importante observar los valores absolutos (entre paréntesis), los cuales ofrecen evidencia sobre la limitadísima participación y su frecuencia. Reiteramos que la mayor participación se registra en las iglesias o parroquias; del total de casos, el 71,1\% lo hace una vez por semana. Otro dato relevante a considerar es que sólo el 0,7\% (6 casos) participa en partidos políticos en el barrio; un caso lo hace con una frecuencia semanal y 5 alguna vez al mes. En la Tabla 2 puede observarse cómo a la baja participación se agrega la baja intensidad que reviste la misma.

Tabla 2.

Frecuencia de la participación en instituciones del barrio, en porcentaje sobre el total de la población. Personas de 18 años y más que residen en La Matanza (2018). En porcentajes

\begin{tabular}{|c|c|c|c|}
\hline Institución del barrio en la que participa & $\begin{array}{c}\text { Una vez } \\
\text { por semana }\end{array}$ & $\begin{array}{c}\text { Alguma } \\
\text { vez al mes }\end{array}$ & $\begin{array}{c}\text { Alguma } \\
\text { vez al año }\end{array}$ \\
\hline $\begin{array}{l}\text { Actualmente participa de sociedad de fomento } \\
\text { de su banio }\end{array}$ & $\begin{array}{l}1,1 \\
(9)\end{array}$ & $\begin{array}{l}0,4 \\
(3)\end{array}$ & $\begin{array}{l}0,1 \\
(1)\end{array}$ \\
\hline $\begin{array}{l}\text { Actualmente participa del centro vecinal de su } \\
\text { barnio }\end{array}$ & $\begin{array}{l}0,4 \\
(3)\end{array}$ & -- & -- \\
\hline $\begin{array}{l}\text { Actualmente participa de partidos políticos en } \\
\text { su barnio }\end{array}$ & $\begin{array}{l}0,1 \\
(1)\end{array}$ & $\begin{array}{l}0,6 \\
(5)\end{array}$ & --- \\
\hline $\begin{array}{l}\text { Actualmente participa de organizaciones } \\
\text { barriales/ternitoriales en su bario }\end{array}$ & $\begin{array}{l}0,4 \\
(3)\end{array}$ & $\begin{array}{l}0,5 \\
(4)\end{array}$ & \\
\hline $\begin{array}{l}\text { Actualmente participa de delegaciones } \\
\text { municipales en su bario }\end{array}$ & $\begin{array}{l}0,5 \\
(4)\end{array}$ & & \\
\hline $\begin{array}{l}\text { Actualmente participa de Parroquia/Iglesia en } \\
\text { su barnio }\end{array}$ & $\begin{array}{r}7,8 \\
(64)\end{array}$ & $\begin{array}{c}2,6 \\
(21)\end{array}$ & $\begin{array}{l}0,6 \\
(5)\end{array}$ \\
\hline $\begin{array}{l}\text { Actualmente participa del comedor comunitario } \\
\text { en su bario }\end{array}$ & $\begin{array}{l}0,6 \\
(5)\end{array}$ & $\begin{array}{l}0,5 \\
(4)\end{array}$ & $-\cdots-$ \\
\hline $\begin{array}{l}\text { Actualmente participa del sindicato en su } \\
\text { barnio }\end{array}$ & $\begin{array}{l}0,1 \\
(1)\end{array}$ & $-\cdots$ & $\cdots$ \\
\hline
\end{tabular}

Fuente: Elaboración propia. 
No obstante, el escaso número de personas que participan se ha analizado en relación a algunas variables, a efectos de comprender mejor quiénes son. Respecto al género, entre las 13 personas que dicen participar en sociedades de fomento del barrio, 8 son varones y 5 mujeres. Este número se repite al observar la relación entre dicha participación y quién aporta mayores ingresos al hogar: entre las personas que participan en sociedades de fomento del barrio, 8 son los mayores aportantes de ingresos al hogar. Esta relación es inversa entre quienes participan en partidos políticos: sobre un total de 6, sólo uno es el que aporta los mayores ingresos mensuales al hogar. En el caso de la participación en iglesias/parroquias el 25,8\% (23) son varones y el 74,2\% (64) mujeres, y el 57\% (51) de éstos son el mayor aportante de ingresos al hogar mensualmente. Otra información interesante para destacar es respecto a la participación en comedores comunitarios del barrio: 2 son varones y 9 mujeres.

El partido de La Matanza puede dividirse en tres cordones geográficos ${ }^{4}$ relacionados con su cercanía a la ciudad de Buenos Aires y el acceso a los servicios públicos. En la Tabla 3 mostramos la participación según el cordón de residencia de los encuestados y encuestadas. No obstante el escaso número de casos, una primera lectura deja en claro que es mayor la participación en el primer cordón en todas las categorías, aunque destacándose en iglesias y parroquias.

Tabla 3.

Participación en instituciones del barrio según cordón de residencia de personas de 18 años y más en La Matanza (2018). En absolutos

\begin{tabular}{|c|c|c|c|c|}
\hline Institución del bario en la que participa & $\begin{array}{c}1^{\circ} \\
\text { Cordón }\end{array}$ & $\begin{array}{c}2^{\circ} \\
\text { Cordón }\end{array}$ & $\begin{array}{c}3^{\circ} \\
\text { Cordón }\end{array}$ & \\
\hline $\begin{array}{l}\text { Actualmente participa de sociedad de fomento de su } \\
\text { banio }\end{array}$ & 4 & 4 & 2 & \\
\hline Actualmente participa del centro vecinal de su banio & 4 & -- & -- & \\
\hline $\begin{array}{l}\text { Actualmente participa de partidos políticos en su } \\
\text { banio }\end{array}$ & 3 & 2 & 1 & \\
\hline $\begin{array}{l}\text { Actualmente participa de } \\
\text { baniales/tenitoriales en su banio }\end{array}$ & 6 & -- & 2 & \\
\hline $\begin{array}{l}\text { Actualmente participa de delegaciones municipales en } \\
\text { su barrio }\end{array}$ & 2 & 1 & 1 & \\
\hline $\begin{array}{l}\text { Actualmente participa de Parroquia/Iglesia en su } \\
\text { banio }\end{array}$ & 46 & 28 & 10 & \\
\hline $\begin{array}{l}\text { Actualmente participa del comedor comunitario en su } \\
\text { banio }\end{array}$ & 7 & 1 & 2 & \\
\hline Actualmente participa del sindicato en su banio & 1 & -- & -- & \\
\hline Total & $\begin{array}{c}57,5 \% \\
(73)\end{array}$ & $\begin{array}{c}28,4 \% \\
(36)\end{array}$ & $\begin{array}{c}14,1 \% \\
(18)\end{array}$ & $\begin{array}{l}100 \% \\
(127)\end{array}$ \\
\hline
\end{tabular}

Fuente: Elaboración propia.

Los datos convergen: la participación no es una actividad de la vida cotidiana de los argentinos. En forma crítica, pensemos algunas preguntas para nuestros datos y propias interpretaciones:

1. ¿Lo que sucede es que la gente tiene miedo de contestar si hace tal o cual actividad y por eso los números no son representativos? Esto sería la aceptación de que la política provoca miedo y, por lo tanto, complejiza y empeora el panorama.

2. ¿Qué sucedió con la “sensación” de politización que se vivió? La respuesta es que territorialmente (“en las bases”) no se comprueba dicha politización y abona nuestra interpretación sobre las fantasías sociales vividas en los últimos años.

3. ¿La gente puede pensar que su participación política se da en otro orden territorial o de “agregación” 
política? Lo que nos llevaría a preguntarnos en relación a 2 sobre la existencia y profundidad del trabajo barrial y territorial de los partidos políticos y movimientos sociales.

Por otro lado, hay que ensayar, también, otra interpretación ante una simple pregunta ¿Qué significa esta no participación? Implica, al menos, una valoración negativa de la política conduciendo a una aparente paradoja: consolidación de la democracia con narrativas “militantes” sin participación política. La vivencia del compromiso y la participación, debe seguir siendo un tópico para discutir lo que es cierto, es que si se conecta con el fuerte carácter "desmovilizador” de la masificación de las políticas sociales el escenario que se compone no es muy alentador.

\section{Ampliación de planes, décadas recibiendo planes y construyendo sensibilidades}

En la actualidad, fuentes informales indican que más de 21.000.000 de argentinos reciben dinero del Estado. Esta cifra se obtendría si se suman el empleo público nacional, provincial, municipal y el entero sistema de seguridad social y programas sociales. Más allá de la posibilidad de discutir estos datos, si se toman datos oficiales, sólo pensando en el empleo público, se encuentra el siguiente escenario:

Figura 1.

Distribución del empleo público según nivel jurisdiccional. Diciembre de 2016

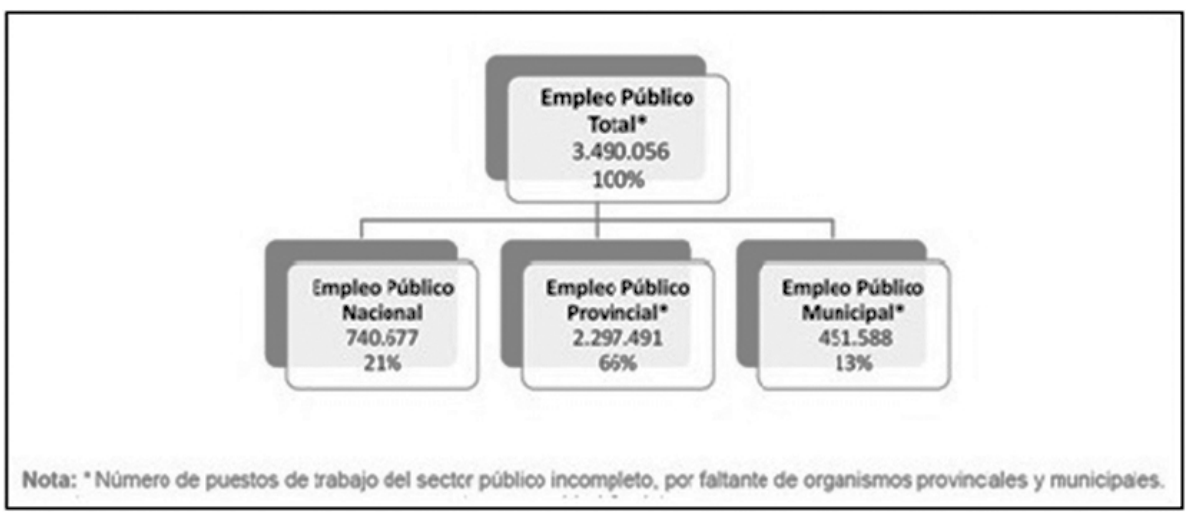

Fuente: MTESS 2017, p. 6.

Más allá de las variaciones posibles de este número, y en virtud de que el dato que se dispone es que los argentinos somos 40 millones, el hecho que alrededor de la mitad del país reciba dinero estatal habla a las claras del enorme y reticular mecanismo de construcción de sociabilidad, vivencialidad y sensibilidad.

Ahora bien, como se puede apreciar en el Gráfico 1, los datos oficiales son de una envergadura muy importante. Si se repara en que, más allá de los montos específicos, en 2014 había dieciséis millones de personas incluidas en el sistema que, por definición, es para "ayudar”, "palear”, “manejar” la pérdida de autonomía de los sujetos ante la pobreza, la discapacidad, el envejecimiento, etc., las experiencias de vida que ello implica y las políticas de las sensibilidades a ellas asociadas claramente tendrán que ver con los conflictos que dichas pérdidas implican. 


\section{Gráfico 1.}

Destinatarios de las políticas de transferencias monetarias por programa, 2005-2014.

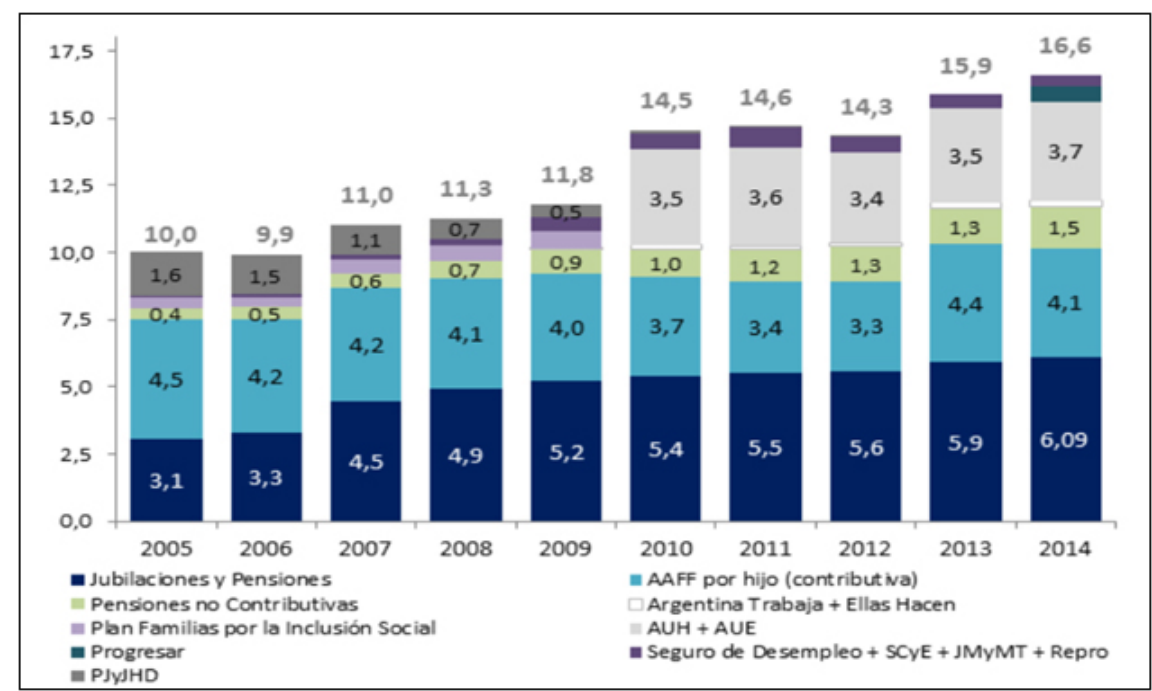

Fuente: Lombardía y Rodríguez, 2015.

En la actualidad, la información del Observatorio Social de la Deuda Social (Tabla 4) consigna el siguiente estado en la recepción masiva de programas sociales:

Tabla 4.

Hogares y población con programas sociales de transferencia de ingresos. Serie Bicentenario (2010-2016) y Agenda para la Equidad (2017-2018)

\begin{tabular}{|c|c|c|c|c|c|c|c|c|c|c|}
\hline & Serie EDSA & 2010 & 2011 & 2012 & 2013 & 2014 & 2015 & 2016 & 2017 & 2018 \\
\hline \multirow{2}{*}{$\begin{array}{l}\text { Hogares con } \\
\text { programas sociales }\end{array}$} & Serie Bicentenario ** & 23,7 & 24,0 & 25,9 & 26,3 & 29,8 & 29,9 & 30,8 & 30,3 & 30,4 \\
\hline & Agenda para la Equidad ${ }^{* * *}$ & 24,5 & 24,8 & 26,7 & 27,2 & 30,8 & 30,9 & 31,7 & 31,0 & 31,2 \\
\hline \multirow{2}{*}{$\begin{array}{c}\text { Personas en hogares } \\
\text { con programas } \\
\text { sociales }\end{array}$} & Serie Bicentenario ** & 31,9 & 31,0 & 33,5 & 34,0 & 38,3 & 39,2 & 40,5 & 39,9 & 40,5 \\
\hline & Agenda para la Equidad ${ }^{* * *}$ & 32,9 & 31,9 & 34,5 & 35,0 & 39,4 & 40,4 & 41,7 & 41,1 & 39,9 \\
\hline \multirow{2}{*}{$\begin{array}{l}\text { Hogares pobres con } \\
\text { programas sociales }\end{array}$} & Serie Bicentenario ** & 56,9 & 56,1 & 61,4 & 60,2 & 64,9 & 64,7 & 68,4 & 68,9 & 59,5 \\
\hline & Agenda para la Equidad ${ }^{* \star *}$ & 54,1 & 53,3 & 58,3 & 57,2 & 61,7 & 61,5 & 65,0 & 65,5 & 61,3 \\
\hline \multirow{2}{*}{$\begin{array}{c}\text { Personas en hogares } \\
\text { pobres con } \\
\text { programas sociales }\end{array}$} & Serie Bicentenario ** & 62,4 & 59,8 & 64,8 & 63,3 & 69,1 & 70,4 & 72,8 & 74,9 & 64,4 \\
\hline & Agenda para la Equidad ${ }^{* \star *}$ & 60,0 & 57,5 & 62,3 & 60,8 & 66,4 & 67,7 & 70,0 & 72,0 & 67,3 \\
\hline
\end{tabular}

Fuente: Observatorio de la Deuda Social Argentina, 2018, p.39. 
En el Informe del Observatorio se sostiene:

"Poco más de 3 de cada 10 hogares en la Argentina percibe algún tipo de programa social, manteniéndose la proporción relativamente estable desde 2014. La cobertura alcanza a casi el 40\% de la población urbana. El alcance de esta cobertura ha tenido un incremento casi sistemático desde 2010, habiéndose estancado durante los último tres años.” (Observatorio de la Deuda Social Argentina 2019, p. 24).

Empleo público y masividad en los programas sociales son dos vectores que: a) “contienen” a una gran cantidad de personas, b) permiten "gestionar” el conflicto y c) retraen a las personas al ámbito privado y de “manejo” del “plan”.

En otros escritos hemos destacado algunos atributos de las intervenciones del Estado sobre poblaciones vulnerables implementadas en las últimas décadas en Argentina. Ellos son la masividad, es decir, la mayor cantidad de programas y sujetos receptores de los mismos (De Sena, 2011); la cobertura de por vida, en donde en cada etapa de vida (desde el embarazo hasta la vejez) existe un subsidio para el sujeto pobre; la intergeneracionalidad, es decir, recibir una ayuda en forma de subsidio de por vida, de madres a hijas/os y nietos/as (De Sena, 2017). Otro elemento, refiere a la ocupabilidad. Los múltiples formatos de programas de atención a las situaciones de pobreza cuentan siempre con una contraprestación, condicionalidad" , una "tarea” o "actividad” que debe realizar la persona que lo recibe. Por un lado, esto puede deberse a la necesidad de "tranquilizar" a los sectores medios y altos no receptores de dichos programas, que son contribuyentes y por tanto de modo solidario permiten una erogación por parte del Estado. Pero también nos interrogamos respecto a estas múltiples facetas de "hacer algo" (De Sena, 2016). A continuación, presentamos algunos pasajes de entrevistas en los que se observan los elementos descriptos, en tanto componentes de un sensibilidad aplanada:

"Entrevista A: Acá en el barrio todos tenemos un plan, nos tiran esto para dejarnos tranquilos (Mujer, 44 años, Lanús, 2010).

Entrevista B: Sí, tienen, muchas amigas (Refiere al Ciudadanía Porteña CP). Y así, vecinas también... (Mujer, 38 años, Ciudad Autónoma de Buenos Aires CABA, 2015).

Entrevista C: El plan Barrio. Yo soy la tercera camada... (Mujer, 25 años, José C. Paz, 2010).

Entrevista D: .. entonce bueno viste ahora ... mi mamá me quiere hacer ahora...[que cobre el plan] a mí viste por el tema del bebé (Mujer embarazada, 16 años, San Isidro, 2010).

Entrevista E: Sí, Ciudadanía la tengo por mi mamá porque vivimos en la misma casa, y yo tengo Estudiar es Trabajar. (...) a mí me dijeron que me inscriba por el hecho que mi mamá cobraba el Ciudadanía, y como yo ya iba a cumplir los 18 años y estaba estudiando dijeron que me anote y vine y me anoté. (Mujer 18 años, una hija, percibe Estudiar es Trabajar y su mamá el CP, CABA, 2015).

Entrevista F: Esto lo tengo desde hace ya, te digo la verdad, tengo, desde el principio, ya hace 16 años.Bastante,lo vengo siguiendo desde que daban papeles, después daban así, no me acuerdo como se llamaba, pero te venía el monto, 10 pesos, 20 pesos. Después cambiaron a la tarjeta.Y desde entonces tengo hasta ahora ya hace 16 años, porque mi hijo más chico era bebé y ahora va a cumplir 17 en julio. [Refiere al CP] (Mujer, 42 años, CABA, 2015).

Entrevista G: Yo me acuerdo del Caja PAN... Mi mamá la iba a buscar(...) Entonces bueno, fui, me anoté, digo, bueno, una ayuda. (...) cuando empezó el programa, es como que salí, y la verdad me sentí re bien, porque conecté con muchas mujeres, que por ahí habían pasado muchas cosas... Yo pasé violencia de género con una pareja, habían pasado cosas en común, y hablar, y compartir momentos, te saca un poco... y bueno, así que... es como que volver a sentirme útil fue. El programa me sirvió para eso.” (Mujer, 37 años, Ellas Hacen, La Matanza, 2017).

Con el aumento de la pobreza a partir de los años 90, se incrementa la cantidad de programas y de personas receptoras de los mismos. Dichos programas estuvieron y están vinculados con el trabajo, la asistencia alimentaria, de servicios de salud, a los que se sumaron subsidios en dinero en efectivo tanto para la compra de alimentos como por la realización de actividades laborales y/o comunitarias. Una información relevante es considerar que a partir del año 2012 se inaugura una política de créditos, primero, para jubilados y pensionados y, desde el año 2017, se amplían a receptores de la Asignación Universal por Hijo (AUH), de Pensiones no 
Contributivas (PNC) y de la Pensión Universal para el Adulto Mayor (PUAM) . La gestión de los distintos programas se realiza desde diferentes ministerios: Trabajo, Salud, Desarrollo social y, a partir del año 2009, se incorpora el ANSES ${ }^{6}$.

El plan aplana (Scribano y De Sena, 2018). Es una modalidad de crear y gestionar sensibilidades. Es un mecanismo intergeneracional de reproducción de posiciones y condiciones pero, fundamentalmente, una manera de sentirse en el mundo.

\section{A modo de conclusión}

Sin participación y aplanados (atrapados en una red de planes) los sectores más pobres de la Argentina viven en una situación cotidiana de represión sistemática de su autonomía, anclados en los fantasmas estructurales y “colgados” en las contingentes fantasías.

En otros lugares hemos explorado los planes de securitización, represión y militarización de la policía en la vida cotidiana, asociadas a la racialización y la segregación (Scribano y Seveso Zanin, 2012); la creciente y estructural violencia contra la mujer en tanto piso de fondo y también en tanto síntoma de muchas otras violencias (De Sena y Scribano, 2013) y puesto en evidencia a los desalojos como mecanismo de persecución y silenciamiento a lo largo de todo el país (Scribano y De Sena, 2016). Siendo estos modestos ejemplos auto referenciales solo una pequeña muestra de la situación de la "represión-en-democracia”.

Fenómenos a los cuales se deben sumar la persecución y represión a los movimientos y organizaciones sociales en contra de la minería a cielo abierto (Machado Aráoz, 2009; Misoczky y Böhm, 2013), la judicialización y muerte de niños, adultos y dirigentes de los pueblos originarios (Agosto, 2013; Gómez Mederos, 2015) y el acoso de los colectivos en lucha contra el monocultivo, el uso del glifosato y las semillas transgénicas.

En este contexto resulta interesante retomar lo sostenido al inicio del presente artículo: donde protesta y participación hubo, plan social queda. La baja participación institucional y social junto a la percepción de programas sociales traman un estado de "represión desapercibida" que implica la dependencia (viven del Estado), el individualismo (deben gestionar su plan) y el consumo autocentrado (sólo tienen espacio para pensar en los niños y en ellas). Juntos, estos tres componentes hacen de la represión física un mecanismo reservado para momentos y actores muy específicos, más allá que sea o no importante en su número. Esta es la gran paradoja de las grandes manifestaciones que, con cierta cadencia e iteratividad, llevan a las calles a cientos de miles de personas. Terminado el episodio, en el día a día la política de las sensibilidades se arma alrededor de la no participación y la gestión de los planes. En una democracia por consumo los recursos los provee el Estado para garantizar la paz social y el margen de ganancia de las empresas.

Es muy difícil que millones de personas que "reciben un cheque del Estado" intenten hacer entrar en crisis a quien le provee de dinero y provocar el cambio social; es muy difícil que en un Estado donde los sujetos participan recibiendo y comprando se comprometan con las instituciones sociales y políticas.

Desde otra perspectiva, es interesante reparar en la diferencia entre narrativas épicas instaladas en el "hablar sobre política” y el "hacer en política” caracterizado por la no participación. En este contexto se inscribe una política de la sensibilidad que contiene, gestiona y privatiza el conflicto.

Ahora bien, al lado, en el mismo territorio, en la misma zanja que inunda y ensucia, en la desazón y el descreimiento, miles de cientos de miles de madres, padres, hijos, hijas, familiares y amigos todos los días performan prácticas intersticiales en base al amor filial (Scribano, 2010b, 2017) donde el otro y los otros se configuran como meta fundamental de la vida desmintiendo el régimen de verdad que impone la sociedad normalizada en el disfrute inmediato a través del consumo. Millones de personas día-a-día se "juegan” por los otros y son estas prácticas intersticiales las que quiebran la desatención y el aislamiento. 


\section{Notas}

${ }^{1}$ Los resultados correspondientes a las ediciones 2010 y 2012 de este estudio pueden consultarse en Scribano et al, 2015.

${ }^{2}$ Refiere a "Principales rasgos de la 'cuestión social' al comienzo del siglo XXI. La Matanza 2017-2018”. Proyecto de investigación PROINCE código PIDC 55 B 206. Secretaría de Ciencia y Tecnología y Departamento de Ciencias Económicas de la Universidad Nacional de La Matanza. Directora: Angélica De Sena. Docentes investigadores: Gómez, Joel; Ibarra, José; Lazarte, Ma. Belén; Panetta, Romina y Val, María Alejandra. Becaria: Bareiro Gardenal, Florencia.

${ }^{3}$ Es menester considerar que si bien el cuestionario admitía la posibilidad de otra institución en la que se participara, en la totalidad de los casos no se registraron otras opciones.

${ }^{4}$ La extensión del partido de La Matanza hace que pueda subdividirse en tres cordones dentro del Gran Buenos Aires, cada uno de ellos con características socio-demográficas y económicas diferentes. El primer cordón se ubica desde la zona limítrofe a la Ciudad Autónoma de Buenos Aires hasta la Av. Monseñor R. Bufano donde comienza el segundo. Éste se extiende hasta la Av. Federico P. Russo, donde inicia el tercer cordón, el cual se extiende hasta su límite con Marcos Paz y Cañuelas. Según información recogida en La Matanza Informa, en el primer cordón el 6,5\% de personas son pobres, en el segundo el 23,8\% y en el tercero el 37\%. Según "Objetivos del milenio en el Municipio de La Matanza. Desarrollo metodológico y estado de situación 2009”, Jefatura de Gabinete Municipio de La Matanza. Programa de Naciones Unidas para el desarrollo (PNUD). Disponible en https://www.cepal.org/MDG/noticias/paginas/5/ 44335/Objetivos_del_milenio_en_La_Matanza.pdf.. Consultado el 29 de enero 2019.

${ }^{5}$ No desconocemos la distinción de los conceptos que en este escrito no se desarrollan dado los objetivos del mismo.

${ }^{6}$ Administración Nacional de la Seguridad Social. Véase: https://www.argentina.gob.ar/anses

\section{Bibliografía}

Agosto, P. (2013). Continuidades coloniales en torno a los saberes y los territorios ancestrales. Onteaiken. Boletín sobre Prácticas y Estudios de Acción Colectiva, (15), 54-70. Recuperado de http://onteaiken.com.ar/ver/ boletin15/2-3.pdf

Askins, K. y Blazek, M. (2017). Feeling our way: academia, emotions and a politics of care. Social \& Cultural Geography, 18 (8), 1086-1105. DOI:10.1080/14649365.2016.1240224

Barnes, M. (2008). Passionate participation: Emotional experiences and expressions in deliberative forums. Critical Social Policy, 28 (4), 461-481.

Boler, M. (2015). Feminist Politics of Emotions and Critical Digital Pedagogies: A Call to Action. PMLA 130 (5), 1489-1496. https://doi.org/10.1632/pmla.2015.130.5.1489

Cervio, A. (2015). Espacio, conflicto y sensibilidad. Los "sentidos de ciudad”, una mirada analítica. Onteaiken. Boletín sobre Prácticas y Estudios de Acción Colectiva, 10 (20), 43-60. Recuperado de http://onteaiken.com.ar/ boletin-no-20

Cervio, A. y Vergara, G. (2017). Segregación socio-espacial, conflictos y sensibilidades: disputas por la movilidad y el desplazamiento en la ciudad de Córdoba, Argentina. Aposta. Revista de Ciencias Sociales, (74), 111144. Recuperado de http://apostadigital.com/revistav3/hemeroteca/acervio.pdf

Colin, C. (2016). Del miedo al orgullo: emociones que conducen la movilización patrimonial. El caso del barrio Matta Sur, Santiago de Chile. Revista Latinoamericana de Estudios sobre Cuerpos, Emociones y Sociedad, 22 (8), 9-20. Recuperado de http://www.relaces.com.ar/index.php/ relaces/article/view/421

Daich, D., Pita, M. y Sirimarco, M. (2007). Configuración de territorios de violencia y control policial: corporalidades, emociones y relaciones sociales. Cuadernos de Antropología Social, (25), 71-88. Recuperado de http://revistascientificas.filo.uba.ar/index.php/CAS/article/view/4379

De Sena, A. (2017). Muchos, ocupados y beneficiarios para toda la vida: Políticas Sociales, Sociabilidades y 
Sensibilidades en Argentina. En Pastor Seller, E. (ed.) Sistemas y Políticas Bienestar Social, una perspectiva internacional (pp. 131-145). Madrid, España: Dykinson.

(2016). La ocupabilidad como forma de política social. Revista sociológica de pensamiento crítico, 10 (2), 35-49. Recuperado de: http://www.intersticios.es/

(2014). Estudiantes universitarios, jóvenes y participación: ni tan claro ni tan oscuro. Revista Lugares de Educação, 4 (9), 49-69.

(2011). Promoción de Microemprendimientos y políticas sociales: ¿Universalidad, Focalización o Masividad?, una discusión no acabada. Revista Pensamento Plural, 4 (8), 36-66. Recuperado de http:// pensamentoplural.ufpel.edu.br/ed-08.htm

De Sena, A. y Scribano A. (2013). Violencia(s) en contexto(s) de pobreza. Formas, voces y "naturalizaciones”. Revista de Sociología, (23), 231-255.

Einwohner, R. (2006). Identity Work and Collective Action in a Repressive Context: Jewish Resistance on the “Aryan Side” of the Warsaw Ghetto. Social Problems, 53(1), 38-56. https://doi.org/10.1525/sp.2006.53.1.38

Fernández Poncela, A. (2013). Movimientos y sentimientos.Revista Latinoamericana de Estudiossobre Cuerpos, Emociones y Sociedad, 13 (5), 9-20. Recuperado de http://www.relaces.com.ar/index.php/relaces/article/ viewArticle/284

Fraser, A. (2016). 'Let’s Be Responsible Citizens! Contesting the agenda of a sponsored call-in radio programme', PiMA Working Paper \#6, https://doi.org/10.17863/CAM.6113

Gamson, W. (1990). The Strategy of Social Protest. Homewood, United States: Dorsey Press.

García-Martínez, V., Guzmán-Sala, A. y Marín-Sandoval, R. (2016). El tránsito de las emociones en la acción colectiva. Análisis del discurso de los jóvenes del \#Yo Soy 132”. Revista Latinoamericana de Estudios sobre Cuerpos, Emociones y Sociedad, 22 (8), 21-32. Recuperado de http://www.relaces.com.ar/index.php/ relaces/article/view/397

Gómez Mederos, R. (2015). El procesamiento al Lof Winkul Newen. Ley antiterrorista y lobby transnacional. Rebelión. Recuperado de http://www.rebelion.org/noticia.php?id=198493

Gould, D. (2009). Moving politics: emotion and ACT UP's fight against AIDS. Chicago, USA: University of Chicago Press.

Hamilton, C. (2010). Moving feelings: nationalism, feminism and the emotions of politics. Oral History, 38(2), 85-94.

Hutchison, E., y Bleiker, R. (2014). Theorizing emotions in world politics. International Theory, 6(3), 491-514. doi: http://dx.doi.org/10.1017/S1752971914000232

Latinbarómetro (2013). Informe 2013. Santiago de Chile, Chile: Corporación Latinbarómetro. Recuperado de www.latinobarometro.org/documentos/LATBD_INFORME_LB_2013.pdfLépore, E.y Moreno, C. (2007). Confianza pública y participación ciudadana en la Argentina post-devaluación”. Observatorio de la Deuda Social Argentina, Boletín No 2. Recuperado de http://bibliotecadigital.uca.edu.ar/repositorio/investigacion/ confianza-publica-participacion-ciudadana-argentina.pdf

Lisdero, P. (2017a).Conflicto social y sensibilidades. Un análisis a partir de las imágenes/observaciones de los saqueos de diciembre de 2013 en la ciudad de Córdoba (Argentina). En G, Vergara, y A. De Sena (comp.) Geometrías Sociales (pp. 65-89). Buenos Aires, Argentina: Estudios Sociológicos Editora. Recuperado de: 
http://estudiosociologicos.org/-descargas/eseditora/geometrias-sociales/geometrias_sociales.pdf

(2017b). Trabajo, cuerpo y conflicto social. La sonrisa telefónica y el trabajo emocional en los Call Centers. En P. Robertt; A. Dávila; P. Lisdero y R.Brauner Ferreira (comp.) O novo espítito do capitalismo no Sul: paralelismos e contrastes (pp. 319-346). Pelotas, Brasil: Editora UFPel.

(2012). La guerra silenciosa en el mundo de los Calls Centers. Papeles del CEIC, 80, 1-31. Recuperado de http://www.identidadcolectiva.es/pdf/80.pdf.

Lincoln, Al. (2018). Participation, political. In (Ed.), The Concise Oxford Dictionary of Politics and International Relations. Oxford University Press. Recuperado de http://www.oxfordreference.com/view/10.1093/acref/ 9780199670840.001.0001/acre-9780199670840-e-978

Linklater, A. (2014). Anger and world politics: How collective emotions shift over time. International Theory, 6(3), 574-578. doi:http://dx.doi.org/10.1017/S1752971914000293

Lombardía M y Rodríguez, K. (2015). La experiencia argentina en políticas de transferencias monetarias durante la última década. Documento de trabajo $N^{\circ} 07$. Secretaría de Política Económica y Planificación del Desarrollo. Ministerio de Economía de la Nación. Buenos Aires, Argentina. Recuperado de https:// www.economia.gob.ar/peconomica/basehome/DT_07\%20la\%20experiencia_03.pdf

Lodola, G y Seligson, M. (2013) Cultura política de la democracia en Argentina y en las Américas, 2012. Hacia la igualdad de oportunidades. LAPOP, Universidad Torcuato Di Tella, CIPPEC, Vanderbilt University.

Machado Aráoz, H. (2009). Minería transnacional, conflictos socioterritoriales y nuevas dinámicas expropiatorias: el caso de Minera Alumbrera. En M. Svampa y Antonelli, M. (Eds.). Minería transnacional, narrativas del desarrollo y resistencias sociales (pp 205-228). Buenos Aires, Argentina: Biblos.

Mc Adam, D. (1998). Orígenes conceptuales, problemas actuales y direcciones futuras, en P. Ibarra (ed.) Los Movimientos Sociales. Transformaciones políticas y cambio cultural. Madrid, España: Editorial Trotta.

Melucci, A. (1989). Nomads of the Present. London: Hutchinson Radius.

(1992) Liberation or Meaning? Social Movements, Culture and Democracy. Development and Change, 23 (3), 43-77.

Misoczky, M. C. and Böhm, S. (2013). Resisting neocolonial development: Andalgalá's people struggle against mega-mining projects Cad. EBAPE.BR, 11( 2), 311-339.

Montana, J. (2017). Accommodating consensus and diversity in environmental knowledge production: Achieving closure through typologies in IPBES. Environmental Science and Policy, 68, 20-27. https://doi.org/10.1016/ j.envsci.2016.11.011

Nelson, J. (2001). Political Participation. In (Ed.), The Oxford Companion to Politics of the World: Oxford University Press. Recuperado de http://www.oxfordreference.com/view/10.1093/acref/ 9780195117394.001.0001/acref-9780195117394-e-0600.

Observatorio de la Deuda Social Argentina (2018). Estancamiento Estructural, Pobrezas Crónicas, Exclusiones Económicas y Desigualdades Sociales en la Argentina Urbana (2010-2018). Buenos Aires, Argentina: Universidad Católica Argentina. Recuperado de http://uca.edu.ar/es/noticias/estancamiento-estructural—pobrezascronicas-exclusiones-economicas-y-desigualdades-sociales-en-la-argentina-urbana_-2010-2018-

Poma, A. (2014). Emociones y subjetividad: un análisis desde abajo de las luchas por la defensa del territorio. Papers. Revista de Sociología, 99(3), 377-401. DOI: http://dx.doi.org/10.5565/rev/papers.602 
Poma, A. y Gravante, T. (2017). Emociones, protesta y acción colectiva: estado del arte y avances. Aposta. Revista de Ciencias Sociales, 74, 32-62. Recuperado de http://apostadigital.com/revistav3/hemeroteca/apoma.pdf

(2016). Las luchas por la defensa del territorio como experiencias emancipadoras. Un análisis de la resistencia contra la presa de San Nicolás, Jalisco México. Desacatos, Revista de Antropología Social, 52, 112127.

(2015a). Analyzing Resistances from Below. A Proposal of Analysis Based on Three Struggles Against Dams in Spain and Mexico. Capitalism, Nature, Socialism, 26(1), 59-76.

(2015b). Las emociones como arena de la lucha política. Incorporando la dimensión emocional al estudio de la protesta y los movimientos sociales. Ciudadanía Activa. Revista Especializada en Estudios sobre la Sociedad Civil, 3(4), 17-43.

(2013). Emociones, protesta y cambio social. Una propuesta de análisis. Revista Latinoamericana de Estudios sobre Cuerpos, Emociones y Sociedad, 5(13), 21-34. Recuperado de http://www.relaces.com.ar/ index.php/relaces/article/viewArticle/242

Rebughin, P. y Scribano, A. (2018). Embodied emotions between constructivism and ontologism. A reflection from the sociology of Alberto Melucci. Social Science Information, 57 (4), 644-661. https://doi.org/10.1177/ 0539018418802995

Romanos, E. (2011). Emociones, identidad y represión: El activismo anarquista durante el franquismo. Revista Española De Investigaciones Sociológicas, (134), 87-106. Recuperado de http://www.jstor.org/stable/ 41304936

Scribano, A. (2018). Politics and Emotions. Houston, USA: Studium Press llc.

Scribano, A. (2017a) Normalization, enjoyment and bodies/emotions: Argentine sensibilities. New York: Nova Science Publishers.

Scribano, A. (2017b). “Amor y acción colectiva: una mirada desde las prácticas intersticiales en Argentina”. Aposta. Revista de Ciencias Sociales, 74, 241-280. Recuperado de http://apostadigital.com/revistav3/hemeroteca/ascribano2.pdf

(2010a). Estados represivos: Políticas de los cuerpos y prácticas del sentir. Revista Brasileira de Sociologia da Emoção, 9 (25), 98-140.

(2010b). Las prácticas del querer: el amor como plataforma de la esperanza colectiva. En M. Camarena Lurhs y C. Gilabert (Coord. )Amor y Poder. Replanteamientos esenciales de la época actual (pp. 17-33). Universidad Intercultural de Chiapas. Razón y Acción, AC. México

Scribano, A., Chahbenderian, F., Cervio, A. y Dhers, V. (2015). Regulación de las sensaciones y construcción de sensibilidades en la Argentina del 2010-2012. Documento de Trabajo del CIES, Nº4. Recuperado de http:// estudiosociologicos.org/portal/regulacion-de-las-sensaciones-y-construccion-de-sensibilidades-en-la-argentina-del-2010-2012/

Scribano, A. y De Sena, A. (2016). La Argentina desalojada: un camino para el recuerdo de las represiones silenciadas (2008-2012). En M. Aguiluz Ibargüen (coord.) Visibilidades de la violencia en Latinoamérica: la repetición, los registros y los marcos (p. 207-238). Ciudad de México, México: Centro de Investigaciones Interdisciplinarias en Ciencias y Humanidades, Universidad Nacional Autónoma de México.

(2018) Flattened: Social Policies and Politics of Sensibilities. En Adrian Scribano Politics and Emotions. (p 78-112 ) .Studium Press LLC, Huston, USA 
Scribano, A. y Seveso Zanin, E. (2012). La cabeza contra el muro. Geopolítica de la seguridad y prácticas policiales. Revista de Ciencias Sociales, 25 (30), 12-30. Recuperado de https://dialnet.unirioja.es/servlet/ articulo?codigo $=4035970$

Summers Effler, E. (2002). The Micro Potential for Social Change: Emotion, Consciousness, and Social Movement Formation. Sociological Theory 20: I, 41-60.

Subsecretaría de Políticas, Estadísticas y Estudios Laborales- MTESS (2017). Seguimiento del empleo público nacional, provincial y municipal. Datos a Diciembre de 2016 (2 Informe Abril). Buenos Aires, Argentina: Ministerio de Trabajo, Empleo y Seguridad Social. Recuperado de https://www.google.com/ search?client $=$ firefox $-b-d \& q=$ Seguimiento + del + empleo $+p \% C 3 \% B A b l i c o+$ nacional\%2C + provincial+y+municipal

Thompson, M. P., y Komporozos-Athanasiou, A. (2015). The role of emotion in enabling and conditioning public deliberation outcomes: a sociological investigation. Public Administration: an international quarterly covering public administration throughout the world, 93 (4), 1138-1151. https://doi.org/10.1111/padm.12188

Vergara, G. (2018). Cuerpos, sensibilidades y acción colectiva (Argentina, 2002). Revista Estudos Feministas, 26(1), 1-19. https://dx.doi.org/10.1590/1806-9584.2018v26n143607

Yang, G. (2005). Emotional Events and the Transformation of Collective Action: The Chinese Student Movement. In: H. Flam y D. King (Eds.) Emotions and Social Movements (pp. 79-98). London: Routledge. 